\section{Nachruf auf Hartmut Rabe}

Am 13. November 2018 verstarb Hartmut Rabe - Leiter des Rabe Verlages Bonn und vielen von Ihnen sicher von zahlreichen phlebologischen Veranstaltungen und Publikationen bekannt. Hartmut Rabe war lange Jahre Mitglied in der Deutschen Gesellschaft für Phlebologie. Seine Arbeit für die Phlebologie begann bereits im vasomed Verlag in den 90er Jahren. Als Verlagsleiter dort arbeitete er viele Jahre mit Eberhard Rabe zusammen und war u.a. maßgeblich für die Erstausgabe der „Grundlagen der Phlebologie“ verantwortlich. Im eigenen Verlag hat er u. a. die UIP-Manuals und die DGPJahresberichte initiiert und redigiert. Auch die im Rabe Verlag erschienene Festschrift
„50 Jahre DGP“ wurde von Hartmut Rabe maßgeblich gestaltet und recherchiert.

Die Deutsche Gesellschaft für Phlebologie verdankt Hartmut Rabe viele wichtige Anstöße und Anregungen. Er wird uns immer in dankbarer Erinnerung bleiben. 